\title{
Door to Surpass Barriers: A Key for Better Utilisation of Dental Services
}

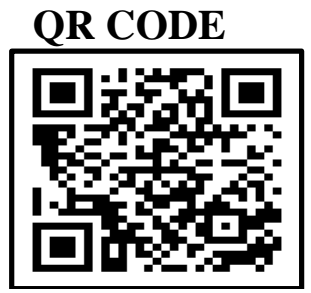

\section{JAGRITI YADAV ${ }^{* 1}$, PRADEEP TANGADE², ANKITA JAIN³, VIKAS SINGH³ ${ }^{3}$ JEEVAN JOSH ${ }^{4}$}

Oral health is an important component of a person's overall health. Oral health care services have long been a concern in underdeveloped nations like India since they are expensive, inaccessible, and underutilized by the general public. Oral health treatment is costly in both the business and private sectors levels and are inexpensive in medical and dental schools, where they are offered by trainees under good supervision. Unawareness of the importance of oral health, a lack of recognized needs, financial restraints, cultural and psychological hurdles are only a few of the challenges that prevent the general public from taking advantage of these services. Oral health insurance, government implementation awareness initiatives, and the development of oral health policies could all help to overcome these obstacles. Every dental surgeon should make a contribution to the cause about this shift in the Indian population's behaviour.

KEYWORDS: Dental Health, Oral Health, Healthcare, Social Class

\section{INTRODUCTION}

The individual's lifestyle and habitat are shaped by the norms of the society to which they belong and people's interactions with the socio-cultural system. The community plays a big part in determining who we are, our health status and illnesses, which have resulted in a significant influence on the programs outcomes focused towards promoting the health of the community. Access to oral healthcare for these marginalized groups is frequently hampered. ${ }^{1}$ Individuals with special needs, ${ }^{2}$ specific ethnic minority groups, ${ }^{3,4}$ those suffering homelessness ${ }^{5}$ people of poor socioeconomic status, ${ }^{6,7}$ and rural communities ${ }^{8}$ among others, have been demonstrated in previous studies to have greater levels of dental caries than the general population.

A majority of dental problems are not self-limiting. Dental problems, if left untreated, can have a negative impact on a person's health and overall quality of life. Oral hygiene at home is required on a regular basis. The best method is to take care of your teeth and have a yearly dental check-up for the purpose of saving one's own teeth. ${ }^{9}$ Access to health services comprises universally (i) a political factor including decisionmaking and agreement by various levels of government in a country, resulting in universal access to health services prioritising and organising services in a systematic manner (ii) Economic and societal implications of intervention devices elements relating to finance, mitigation, or elimination (iii) the system's organisation, the users obstacles commencing with interaction with the service and ending with the resolution and (iv) Understanding the health-disease the users first transitions, beliefs, values, and traditions, via comprehensive actions and respect for individuals, technical-scientific training and cultural competency. ${ }^{10}$

\section{COMMON PROBLEM WITH ORAL HEALTH CARE DELIVERY SYSTEM ${ }^{\prime \prime}$}

1. Resources are insufficient

2. Emphasis on prevention and public health is insufficient.

3. Goals are unclear.

4. Lack of public involvement and accountancy.

5. Imbalance of distribution of services.

6. Scanty organisation and management

- Poor planning

- Administration not unified

- Little emphasis on evaluation

6. Manpower planning and use of auxiliaries failure.

7. High professional standards not being promoted.

8. Dental training not align to health service goals.

9. Dental research does not sufficiently dispose to health care needs and prevention.

10. Unclear strategies for implementing policies.

11. Approach problems.

\section{DENTAL SERVICES IN INDIA:}

India is a developing country with 1.39 billion population. Moreover $70 \%$ of Indian population inhabits in rural areas with mini health care facilities 
and more share of health facilities is taken up by the urban population. Eventually in urban areas poor people are neglected a lot in terms of health and oral health issues. However there is a huge oral health inequality among the mass rural population. ${ }^{12}$

\section{BARRIERS TO ACCESS THE ORAL HEALTH IN INDIA $^{12,13}$}

1. Knowledge and Values: Person those in need of oral health care are unaware of oral disease prevention and are unaware of their clinical need. The general public frequently does not recognise the significance of oral health, considers it to be separate from and secondary to one's overall health. Many decision-makers in government do not recognise or appreciate oral health as a part of one's overall health and dental health care is pushed to the sidelines in favour of general health care. Health has been relegated to a lower priority policy.

2. Accessibility Issues: Due to regional disparities, many people in need do not have access to an oral health provider in their area. Much of the oral health workforce is unprepared to provide culturally competent care to a diverse population, including people with complex medical and psychological conditions, developmental and other disabilities, the very young and the elderly, tribal or rural areas, and people with complex medical and psychological conditions or developmental and other disabilities.

3. Affordability Issues: Many underprivileged communities are unable to obtain and afford dental care. Some of the underserved are unable to get services due to their financial circumstances. In India, dental insurance is almost non-existent.

4. Systemic Barriers: In India's oral health care delivery system, there are numerous systemic impediments. Health services are distributed inequitably with the bulk of dentists based in cities and urban places, and just a few dentists practice in locations where the bulk of the population resides. Due to a severe scarcity of dentists in government services, the majority of health care services are given by private practitioners and dental institutions by trainees, raising the expense of quality oral health care services and making it unaffordable for the majority of India's rural population. There is a dearth of research on the delivery and utilisation of oral health care. Oral health records, statistics, and a dental treatment audit for the area served are not readily available.
5. Patient Problems: The bulk of the Indian population has a dread of dental care, which prevents people from obtaining treatment. The processes at the front desk and in the waiting room can take a long time. Fear of white coats and bright lights, clinical odours, feeling vulnerable, lack of perceived necessity for frequent dental checkups, high expense of dental treatment, time away from work, and taboos/misunderstandings about dentistry are other important barriers to patients receiving oral health care.

6. Quality of Dental Workforce: Another significant difficulty is ensuring that future generations have access to a high-quality workforce. Dental education has become a business as a result of increased college commercialization, and the profession's ethical core has eroded. With the passage of time, the moral standards of the workforce have deteriorated, with the majority of the labour focusing on making money. The enormous growth in some specialisations, the mushrooming of continuing education courses, and the poor maintenance of their standards have all been highlighted as reasons why the workforce should have its own code of ethics. In addition, students who are well-qualified and of high caliber should be encouraged to pursue careers in the field. Like the dentists who came before them, many of the students entering dental schools did so merely because they wanted a dental education or an alternative to medicine.

\section{ACTION FOR RESOLVING UTILIZATION PROBLEMS}

1. Improving the delivery of oral health care systems.

2. Identifying the population's oral health care requirements and demands.

3. Careful planning and the establishment of realistic oral health objectives.

4. Ensuring that health professionals are adequately compensated.

5. Making the best use of auxiliary personnel and providing health education

6. Regular dental camps and the use of a mobile dental care office/unit

7. A shift in dentistry attitudes toward professionalism and social responsibility.

8. Proper resource development and utilization.

Teamwork and intersectoral coordination are essential for effective use of oral health care services. This can be accomplished by working together between the public and private spheres sector with government 


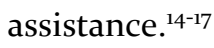

\section{INSTITUTIONS OF DENTISTRY}

Adoption of a geographical area/ village/ school/ special centre such as old age homes, orphanages, etc. by dental institutions should be done. Satellite centres can be established in rural and underserved locations to give oral health care services to residents at no cost or at a reduced cost. The use of a mobile dentistry van can be done to reach out to far-flung locations. Dental workforce interns should be directed to conduct oral health awareness and preventive programmes, as well as this will help to build a community-oriented approach. Oral health education can be imparted by PHC health professionals and school teachers. ${ }^{17,18}$

\section{BODIES OF PROFESSIONALS}

DCI should take the lead and implement competencybased, community-based training during an internship. ${ }^{19}$ IDA, local non-profits, and corporations companies should strive to invest a significant amount of money. Particular attention needs to be paid to oral health. ${ }^{18}$

\section{GOVERNMENT}

For remote areas, use the services of young graduates on a contract basis. The foundation of infrastructure improvements or dental clinics needs to be addressed at the PHC level. In India, however, there is no oral health policy. Although drafts have been created, they have not yet been implemented. As a result, there is a pressing demand for a separate budget and a national oral health policy and a budget for dental health. There is a need to reduce taxes on toothpaste and dental products to make them more accessible to the general public and dentists, lowering costs factor. Local production of these items is also a plus. Oral health should be a part of everyone's daily routine of general well-being among the general public. ${ }^{13,20,21,22}$

\section{CONCLUSION}

There are numerous obstacles to expanding oral health care in India. The greatest difficulty is the lack of qualified dental health planners. Because there are no dentists in government decision-making organisations, dentistry is at the mercy of medical experts, who typically take the lion's share of the small funds sanctioned by the government for their own profession. Health education and the creation of an effective health-care system that is well-communicated are essential. There have been a slew of solutions proposed to overcome these obstacles, but there is no data to back up their efficacy or cost-effectiveness.

\section{REFERENCES}

1. Guay AH. Access to dental care: solving the problem for underserved populations. J Am Dent Assoc. 2004; 135: 1599-605. https://doi.org/10.14219/jada.archive.2004.0088.

2. Owens PL, Kerker BD, Zigler E, Horwitz SM. Vision and oral health needs of individuals with intellectual disability. Ment Retard Dev Disabil Res Rev. 2006; 12: 28-40. https://doi.org/10.1002/mrdd.20096

3. Dietrich T, Culler C, Garcia RI, Henshaw MM. Racial and ethnic disparities in children's oral health: the National Survey of Children's Health. J Am Dent Assoc. 2008;139: 1507-17. https://doi.org/10.14219/jada.archive.2008.0077

4. Flores G, Tomany-Korman S C. The language spoken at home and disparities in medical and dental health, access to care, and use of services in US children. Pediatrics 2008;121: e1703-e1714. https://doi.org/10.1542/peds.2007-2906.

5. Conte M, Broder HL, Jenkins G, Reed R, Janal MN. Oral health, related behaviours and oral health impacts among homeless adults. J Public Health Dent. 2006; 66: 276-8. https://doi.org/10.1111/j.1752-

7325.2006.tbo4082.x.

6. Costa SM, Martins CC, Bonfim Mde L, et al. A systematic review of socioeconomic indicators and dental caries in adults. Int J Envrion Res Public Health. 2012;9:3540-74. https://doi.org/10.339o/ijerph9103540

7. Dye BA, Arevalo O, Vargas CM. Trends in paediatric dental caries by poverty status in the United States, 1988-1994 and 1999-2004. Int J Paediatr Dent. 2010;20: 132-43. https://doi.org/10.1111/j.1365-263X.2009.01029.X 8. Skillman SM, Doescher MP, Mouradian WE, Brunson DK. The challenge to delivering oral health services in rural America. J Public Health Dent. 2010; 70 (Spec Iss): S49-S57. https://doi.org/10.1111/j.1752-7325.2010.00178.x 9. Jain VK, Sequeira P, Jain J, Chancy U, Maliyil MJ, Bhagwandas SC. Barriers in utilization of oral health care services among patients attending primary and community health centres in Virajpet, South Karnataka. Natl J Med Dent Res. 2013;1:39-47.

10. Assis MMA, Jesus WLA. Acesso aos serviços de saúde: abordagens, conceitos, políticas e modelo de análise. Ciência \& Saúde Coletiva 2102; 17(11);2865-75. (In Portugese). $\quad$ https://doi.org/10.1590/S141381232012001100002

11. Plamping D, Bewley R N, Gelbier S. Dental health and ethnicity. $\mathrm{Br}$ Dent J. 1985;158(7):261-3. https://doi.org/10.1038/sj.bdj.4805585 
12. Parkash H, Duggal R, Mathur VP. Formulation of Guidelines for Meaningful and Effective Utilization of Available Manpower at Dental Colleges for Primary Prevention of Oro-dental Problems in the Country. A GOI- WHO Collaborative Programme, 2007:1-56.

13. Lal S, Paul D, Vashisht BM. National Oral Health Care Programme (NOHCP) implementation strategies. Indian J Community Med. 2004;29:3.

14. Tandon S. Challenges to the oral health workforce in India. J Dent Educ. 2004;68(7):28-33.

15. Petersen PE. The World Oral Health Report 2003: continuous improvement of oral health in the $21^{\text {st }}$ century--the approach of the WHO Global Oral Health Programme. Community Dent Oral Epidemiol. 2003; 31:3-23.

16. Oral Health: ICMR Bulletin, Volume 24, April, 1994ICMR, New Delhi.

17. Bali RK, Mathur VB, Tewari A, Jayna P. National oral health policy for India formulated by Dental Council of India, 1994.
18. National oral health care programme implementation strategies, project of DGHS, MOH\&FW. Govt. of India. Submitted by Hari Parkash, Project Director, Naseem Shah, Addl. Project Director, Department of Dental Surgery. AIIMS, Ansari Nagar, New Delhi.

19. Dental Council of India. Notification of revised regulations, 2007. Gazette of India $3^{\text {rd }}$ amendment, October $9^{\text {th }}, 2007$

20. Lea, RA. World Development Report Investing in Health. Forum for Development Studies 1993;20(1):1147. https://doi.org/10.108o/o8039410.1993.9665939

21. Lal S, Mohan B, Punia MS. Health and Social Status of Senior Citizens in Rural Areas. The Indian Journal of Community Medicine 1997;9(3):10-17.

22. Kakatkar G, Bhat N, Nagarajappa R, Prasad V, Sharda A, Asawa $\mathrm{K}$, et al. Barriers to the utilization of dental services in Udaipur, India. J Dent (Tehran) 2011;8:81-9. 